\title{
Earth system science for the 21st Century: towards truly sustainable development
}

\begin{abstract}
Our ultimate resources come from the Sun and the Earth system. At this time we face a world crisis in energy, water and soil resources. Global pollution problems are increasing in almost all nations and our climate is changing. There is an urgent need to use our vast knowledge with a new wisdom and this requires new integrated teams of experts to provide the best alternatives for the needed new development problems. These teams must include economists, engineers and a broad spectrum of scientists. Today it is possible to produce clean energy, stop soil erosion, clean water and reduce and use wastes of many types. There is a great need to improve natural science education at all levels. All people must know how our planet works and that fluctuations, some inevitable, some controllable, will occur and that we must prepare for them. And it is clear that protecting the environment, eliminating pollution, preserving biodiversity is good economics. Ecology-Economy cannot be separated.
\end{abstract}

\section{Introduction}

It is difficult to comprehend the future impact on the earth system the human population increase expected next century. Barring some vast (but not impossible) catastrophe, our numbers will reach over 10 billion. Most of this increased population will live in urban areas with all the complex needs such as improved transport systems, geohazard reduction, and waste management. The situation was well stated recently by Koshland (the former editor of Science) 'First of all, it is important to identify the main villain as overpopulation. In the good old days (viewed through the myopia of nostalgia), the water, air, flora and fauna existed in an idyllic utopia. But, in truth, there were famine, starvation, horses and buggies that contributed to pollution, fireplaces that spewed forth soot from burning soft coal, and water contaminated with microorganisms. The humans were so few, and the land so vast, that these insults to nature could be absorbed without serious consequence. That is no longer true.'

There is a leading question which all educated world citizens must ask. Can we provide adequately for the next five billion without destruction of the most fundamental components of the life support system? This century has been truly remarkable. The scientific giants of the early 1900s (Einstein, Rutherford, Planck, Bohr,...) wrote the rules of modern science and technology, the relations between energy and matter. Their work has stood the test of time remarkably. Their new science led to our present age of observation and information technologies. In large part they contributed to the new medical science which has led to our greater average longevity and the dramatic decline in infant deaths around the world, trends which continue. At the same time, our information systems, in particular television, have led to a new age of expectation. In the forties,
Aldous Huxley wrote that we have treated nature with greed, violence and incomprehension. Our planet has become small, and our future common, as stressed in the famous report of the World Commission on Environment and Development, (1987), the Bruntland Report.

The word 'sustainable' has become popular. It is a simple concept and requires the answer to a simple question--'Will I leave the planet in better condition for all species who support me and follow me?' In the recent report from the New Delhi Population Summit (Graham-Smith, 1994), Sir Michael Atiyah, president of the Royal Society of London wrote, 'Most of the problems we face are ultimately consequences of the progress of science, so we must acknowledge a collective responsibility. Fortunately, science also opens up possibilities of alleviating our problems, and we must see that these are pursued.' In the same volume, Sir Crispin Tickell, former British Ambassador to the U.N. wrote 'It would be nice to think that the solutions to some of our present problems could be drawn from past experience, but in this case the past is a poor guide to the future. Our current situation is unique.'

When we consider the life support system and the future problems faced by Homo sapiens, certain key areas are obvious. They include (in no order of priority):

atmospheric chemistry;

the radiation field;

energy resources;

water resources;

food resources;

materials;

waste management;

geo-fluctuations, climate fluctuations, and the need for surplus, and

biodiversity for security.

In these brief notes I wish to consider the emerging role of the earth system sciences in achieving sustainable development and providing the necessary resources for all people. It is interesting to note some recent comments in leading journals 'Earth Sciences, job prospects on shaky ground' (Holden, 1994); 'Geological programs come under threat' (Macilwain, 1994); 'Geology is under attack' (Rossbacher, 1995). Are the earth sciences not needed for future sustainable development (Fyfe, 1994)? In a recent editorial in Chemical Engineering News (1995), Heylin quotes Stokes of Princeton, 'Better prospects for a new contract for science lie with common recognition of the importance of what he calls use-inspired basic research. He says basic science and technology move ahead together, each, in turn, inspiring and supporting the other in an endless overlapping process. At times, basic science does indeed trigger new technologies, even new industries. Equally, technological needs inspire basic research'.

During the periods of conflict as in the period 1939-45, most scientists became applied scientists. But today, we face a global crisis of far greater magnitude than that of the last world war, the crisis of our survival and responsibility to future generations. We must respond. 


\section{Geologic structures-recent events}

As never before, there is need for highly precise geological mapping on scales appropriate to the development problems being considered. Such maps must be precise in describing the timing of events and must be precise in three dimensions. New dating techniques such as those which use cosmic ray induced isotopes can give a new precision on recent fault-fracture motions, surface erosion and the like. For example, if we consider the growth of megacities, the geological knowledge required to prevent or reduce costly engineering mistakes (e.g. Kobe, Japan) to provide and protect water, to prevent pollution etc., is of a detail and range far beyond most present mapping systems. Recent studies, as with the German deep drilling experiment (the KTB), clearly show that our techniques for deep remote sensing are far from adequate today. I was recently on a field trip with an excellent group of Portuguese (Lisbon University) structural geologists. They were concerned with mapping a region of some interest in terms of a site for nuclear waste disposal. The region was well known for some major fault structures. But their detailed studies, clearly revealed the complexity of the stress patterns and showed that micro-fault systems were present with a frequency distribution of tens of meters. This type of detail is essential to the planning of any major engineering project. At a recent meeting in Norway, Swedish geologists reported on the use of good maps in planning the exact location of new highways resulting in large cost reductions. I will return to other aspects of the types of information required in modern maps below with reference to specific development problems.

\section{Energy problems}

At the present time, the bulk of world energy comes from the combustion of coal, oil and gas. all these resources are non-sustainable, natural capital. The thoughtless waste of such valuable resources is a global disaster. Of the fossil carbon sources, only coal and certain types of carbon-rich sediments have resources of interest for more than a few decades. In a general way, there has been little change in burning technologies: —add air-burn-and exhaust to the atmosphere.

There is no need here to discuss the potential future impacts of the climate changes related to the fact that we have rapidly changed the chemistry of the atmosphere. We normally discuss $\mathrm{CO}_{2}, \mathrm{CH}_{4}$, and acid compounds. But as we have stressed previously (Fyfe and Powell, 1995), many coals contain significant quantities of all halogens $\mathrm{F}, \mathrm{Cl}, \mathrm{Br}$, I and the steadily increasing ozone catastrophe may be influenced by such combustion. In 1997 the ozone hole over the Arctic reached a record size. Also, time after time, the detailed chemistry of coal and coal ash, is not well known and many coals have significant quantities of elements like uranium and arsenic, and an array of heavy metals immobilized in the reducing, sulfur-rich, medium of coal. Some create problems but many may be useful.

It is certain that nations like China and India will depend on coal for decades to come. Can we change the technology at reasonable cost? Can we reduce the environmental impact of coal combustion? I think the answer is positive. We have been studying the fixation of $\mathrm{CO}_{2}$ and organics in the cracked, permeable basalts in the caves of Kauai, Hawaii, deep beneath a very heavy forest cover. Every crack is covered with white stuff (silica, clays, carbonates) formed by the action of organics with the basalt, a process mediated by ubiquitous bacterial biofilms. We now know that bacteria can live to depths of over four kilometer, up to $110^{\circ} \mathrm{C}$, in favourable locations (Pedersen, 1994 and this issue p.7). Can we use such processes to fix the exhaust gases of coal combustion? For sure, certain rock types will be better than others and volcanics with Ca-feldspars and other Fe-Mg phases should be ideal as in Hawaii. Recently on a field trip in China (east of Beijing), we discussed the possibility of using their rapidly exploited oil-gas fields for disposal of wastes of many types.
If a basin can isolate oil-gas for millions of years, it surely has capacity to isolate wastes. And generally, oil field structures are well known. A recent publication (Hitchon, 1996) discusses the possibility of combustion gas disposal in sedimentary basins (Fyfe, 1997).

The growing knowledge of the deep biosphere also raises the possibility, with certain types of carbonaceous sediments, of using microorganisms for in situ methane and hydrogen production. In place of opening deep mines with all the related water pollution problems could it be possible to produce bio-gas (Fyfe, 1996)?

But ultimately, the world must move to solar energy of all types (photovoltaics, wind, tidal) and geothermal energy. There is no shortage of energy sources on this planet. Wind energy use is increasing across the world and photovoltaic devices are becoming more efficient and cheaper (New Scientist, 1995). Geothermal sources are normally associated with regions of high heat flow (volcanic systems) but for some purposes (city heating, greenhouses and aquaculture systems), the normal geothermal gradient can provide background heating. All such potential use requires exact knowledge of deep geologic structures, porosity, permeability and geochemistry.

At the present time only a small fraction of world energy is provided by hydro-electricity. There are regions of the world where there is still potential with river systems (e.g. parts of Africa, Brazil). But there are problems. River flow, runoff, is necessary to keep the land surface clean, particularly with species like salts. Climate, rainfall, is not constant as we have seen dramatically in current years and in dry periods, runoff may be greatly reduced. We now know that major fluctuations and changes in runoff patterns can greatly perturb the marine biomass and even ocean current patterns which in turn can perturb local and global climates (e.g. the Younger Dryas cold event, Fyfe, 1993).

\section{Water}

According to Postal (1992), today, forty nations have a crisis of water supply. In many places, uncontrolled extraction of ground water (mining) is being used to promote non-sustainable increase in food production. In vast areas, bad water management has led to salinization of soils and massive pollution by agri-chemical residues. I was recently in Calcutta and, with their Institute for Man and the Environment, was introduced to their major problem of groundwater arsenic pollution which has led to serious health problems with very large numbers of people. Where does the arsenic come from? This problem is not solved but arsenic compounds have been used for a long time in rodent control.

In the developing world, there are few places where the total water cycle is adequately described. While sea level is slowly rising, in many sensitive coastal regions, land subsidence and apparent sea level rise is associated with subsidence and compaction, following the mining of groundwater. Again, exact geoscience is required to describe the water resource potential of any region and to live with the natural fluctuations in precipitation. Recently, Karl et al. (1997) have described changes in weather patterns. On a planet growing warmer there will be more evaporation and more rain somewhere. The new precipitation patterns must be described. Record floods are occurring in many places.

\section{Soil}

At this time, at least one billion humans do not have an adequate supply of well-balanced, nutritional food (Sadik, 1989). Across the world, wood is becoming an expensive and declining commodity. Despite the electronic revolution, the use of paper products is increasing (per capita, three-fold in the last 40 years). And the world's marine resources are declining at an alarming rate. Sustainable food-fiber production depends on climate, climate fluctuations, soil quality and water resources. Knowledge from the geosciences is 
involved in all these parameters. Given that we are not adequately providing nutrition for the present human population, what are the prospects for the next five billion?

All organisms require a large array and balance of the chemical elements (about 50) for efficient production of the organics needed for life. The geochemistry and mineralogy of soils are critical in estimating the capacity of a soil for sustainable organic productivity. According to the Worldwatch Institute, topsoil loss globally is approaching $1 \%$ per year. The technologies exist now for erosion and salinization control but such technologies are not adequately used. But there is great need for new soil maps which clearly show good soils, soils for forests only, and leave it alone! (Fyfe, 1989; Darnley et al, 1995).

Given the chemical and physical properties of a soil, additives may greatly enhance bio-productivity. Often such additives require the addition of simple mineral materials containing species like $\mathrm{K}$, $\mathrm{Mg}, \mathrm{Ca}, \mathrm{P}$ and appropriate trace metals like $\mathrm{Co}$, Mo, etc. which may be critical in biofunctions like nitrogen fixation. The useful types of additives may be closely linked to soil type and climate. For many situations, as with the laterite soils of the humid tropics, slow release, mineral fertilizers ( $\mathrm{K}$ in feldspars, rock phosphates) may be more effective and less wasteful than soluble chemical fertilizers. Geochemists and clay mineralogists must become more involved in agriculture!

\section{Materials-minerals-mining}

Advanced societies use about 20 tonnes of rock per person per year for their needs. Most is for various forms of construction, highways, buildings, ceramics, etc. Giant mining operations include those for fertilizers, ores like iron, and coal mining. It is amazing but humans in general are ignorant about where their resources come from, the impacts on the ecosphere, geosphere, hydrosphere of mining operations. With modern understanding of earth convection, our understanding of the resource base and prospecting strategies have dramatically increased. If the world needs more copper, we know where to look and we find it.

But because historically, mining technology has been careless, increasingly many large companies move to developing countries with less stringent environmental laws. For example, I was amazed when the North American Free Trade Agreement (NAFTA) was signed, it was clearly stated that local environmental regulations apply. What of the future of the use of mineral resources? For a population of at least 10 billion projected for next century, we must consider the human modification of $100 \mathrm{~km}^{3}$ of rock per year. Most will be ripped from the near surface, but much from increasing depths where mining perturbs the groundwater resources.

First, the world must move to more efficient recycling and for this to be successful requires careful quality control at all stages of the use-mining to fabrication. In mining, there must first be careful 3D mapping of structures, permeability, porosity, faulting, etc. to accurately assess the environmental impacts. There is great need for extreme quality control in the extraction of ore materials. The total geochemistry must be known, the desirable and the undesirable elements. Such data must be available to plan the mining technology and to assess the environmental impact of the operation. Waste products from mining must be studied for potential uses in construction, soil re-mineralization, etc. The growing knowledge of microorganisms at depths (now over $4 \mathrm{~km}$ ) opens a host of new technological opportunities. Silica secreting organisms might be used for permeability control. Metal secreting organisms can be used for removal of heavy metals as has been well demonstrated. And a host of new possibilities must be considered for 'in situ' metal extraction via sulfide oxidizing species. The same is true for 'in situ' methane production from carbonaceous sediments. With all such things there is need for cooperation between geologists, geo-microbiologists, hydrogeologists, engineers and economists. Far too little thought has been given to the end use of mines. In some cases by careful plan- ning, these could become waste disposal sites for urban areas, a growing world problem.

I think there is no doubt, that with the correct team for planning from the start, the environmental impact of extracting resources from the crust can be vastly reduced. And I am sure that in many cases, the long term economics of the operation will be improved. We must also watch for new needs. I was interested to read in the British journal The Economist, that there is a world shortage of high purity silicon for modern electronic devices, and soon we will see vastly increased use of photovoltaics. For such purposes, there is a giant difference between $99.99 \% \mathrm{SiO}_{2}$ and $99.9999 \% \mathrm{SiO}_{2}$.

I have always been intrigued by the possibilities for use of near ocean ridge sites for metal extraction and energy production ( $\mathrm{cf}$ the Salton Sea Thermal fields). On Canada's well-described Juan de Fuca system, by drilling through the impermeable, sediment cover with thermal gradients of up to $300^{\circ} \mathrm{C} / \mathrm{km}$, one might simultaneously extract metals and energy.

\section{Waste management}

This century will go down in history as that of careless technologies and waste production. There is no doubt that the long term costs can be staggering (as with the arsenic pollution in India mentioned above). The complexity of modern wastes is enormous, from organics, to radionuclides, urban garbage, etc. And it is amazing that the nuclear industries developed before any serious attention was given to wastes-the we will do it when necessary philosophy. Ontario, Canada, where nuclear electricity dominates the system, now estimates that it will spend at least 15 billion dollars on nuclear waste disposal in the next decades and at this time no 'best' site has been proposed. And it is strange that only recently has a combustion gas like $\mathrm{CO}_{2}$ been considered a waste product. Combustion has changed the concentration of many critical components of the Earth's atmosphere.

I think the time has come to drastically change our philosophy on wastes. First we must precisely describe the nature of waste, chemistry, etc. Then we must search for uses for the waste and recognize that time after time it can be a resource. Denmark recycles $97 \%$ of its paper, Canada $17 \%$. And the secret of domestic waste management is the five minutes a day spent in separating the components. As mentioned above, we have shown that by using careful geochemistry, many types of coal ash (but not all) can be a valuable soil additive. The same is true for most urban sewage as long as it is not mixed with other toxic wastes from say the chemical industries. Again we need teams of the appropriate scientists, not just engineers! One case I would like to again emphasize is that of the gas products from combustion, $\mathrm{CO}_{2}, \mathrm{NO}_{\mathrm{x}}, \mathrm{SO}_{\mathrm{x}}$, and as we have shown with halogen-bearing coals which are common, possible halogenorganics. Are the latter partly responsible for the growing problems of stratospheric ozone destruction? As mentioned above, can we dispose of these gases below ground and not simply vent to the atmosphere? The cost reduction on public health of reducing all the lung problems might well cover the additional engineering costs. Japan is seriously considering the marine dumping of $\mathrm{CO}_{2}$ (Fyfe, 1997).

Every waste product requires unique approaches. Many wastes can be resources, and for most secure disposal is possible. For geological disposal we require a new precision in the total description of the subsurface environment.

\section{Geo-fluctuations}

There is no need here for lengthy discussion of the problems of the inevitable geo-fluctuations that occur. The Earth environment is not, never was, never will be, constant. Causes of fluctuations, the year without summer, are complex but must be considered in the life support system. They imply that for security there must be surplus and there must be biodiversity. I think one can predict with certainty, that 
given population growth and present planning systems, the next events like the mega-volcanic eruptions of early last century, will see a vast social catastrophe unless we are prepared to plan now and face the new realities.

\section{Conclusion}

As world human population continues to grow, to move to over ten billion next century, the need for exact geoscience must be a priority in planning the needed future development of the support systems. And there is urgent need to improve the communication and effective cooperation between all the experts in modern science and technology, and economists, engineers, politicians and all educated citizens. At this time Europe leads in demonstrations that sound economic and environmental policies are not in conflict but must form a working partnership. We must and can reduce pollution and wastes. We must recognize the limits of the Earth system, we must develop holistic natural science. Given the future numbers of humans on Earth, the cost of errors will become intolerable. Earth and planetary science must and can be introduced into our school curricula at all levels with the objective of education for global responsibility.

\section{References}

Brown, L. R., 1995. State of the World, 1995. 255 p (W.W. Norton \& Co., New York).

Darnley, A.G., Björklund, A., Bølviken, B., Gustavsson, N., Koval, P.V., Plant, J.A., Steenfelt, A., Tauchid, M. Xie, X., Garrett, R.G.\& Hall, G.E.M., 1995: A global geochemical database for environmental and resource management. UNESCO Press, 122pp.

Fyfe, W S, 1989. Soil and global change. Episodes, 12:249-254.

Fyfe, W S, 1993. The life support system in danger: challenge for the earth sciences. Earth Science (Japan), 47, No. 3:179-201.

Fyfe, W S, 1994. The role of Earth Sciences in society. Nature and Resources, UNESCO, 30:4-7.

Fyfe, W. S., 1996. The Biosphere is going deep. Science, . 273: 448.

Fyfe, W.S., 1997. Can we control, reduce, combustion gas emissions from stationery power facilities? Episodes 20:1.

Fyfe, W S and Powell, M A, 1995. Halogens in coal and the ozone hole, Letter to the editor. Chemical Engineering News, (American Chem. Soc.) April 24:6.
Graham-Smith, F. (Editor), 1994. Population-the complex reality. The Royal Society London, $404 \mathrm{pp}$.

Heylin, M, 1995. Science for the 21st century, Chemical Engineering News, (American Chem. Soc.) March 13:5.

Hitchon, B. (Editor), 1996, Aquifer disposal of carbon dioxide. Geoscience Publishing Ltd., Sherwood park, Alberta, Canada, 165 pp.

Holden, C., 1994. Job prospects on shaky ground. Science, 266: 1316.

Karl, T.R., Nicholls, N. And Gregory, J. 1997. The coming climate. Scientific American, 276, No.5,78-83.

Macilwain, C., 1994. Geological programmes come under threat. Nature, 372:715.

Pedersen, K., 1994. The deep subterranean biosphere. Earth Science Reviews, 34:243-260.

New Scientist, 1995. Cheap solar power, January 14:11.

Postal, S., 1992. Last oasis - facing water scarcity. 239 p (W.W. Norton and Co.: New York).

Rossbacher, L A., 1995. Geology is under attack. Geotimes, Feb.:

Sadik, N, 1989. The state of world population, 1989. 34 p (United Nations Population Fund, U.N.: New York).

World Commission on Environment and Development, 1987. Our Common Future.383p (Oxford University Press: Oxford)

W.S.(Bill) Fyfe, the former President of IUGS, is a graduate of the University of Otago. He has been a researcher and teacher at Otago, Berkeley, London, Manchester and Western Ontario where he became Dean of the Faculty of Science. He has been awarded many academic honours in geoscience and has been $a$ visiting lecturer or professor at numerous institutions around the world. His interest in geochemistry, and the applications of geoscience to environmental management, has taken him to developing countries in all parts of the world.

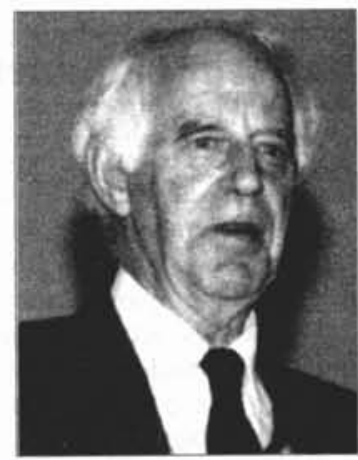

